\title{
A newly identified mutation in the PEX26 gene is associated with a milder form of Zellweger spectrum disorder
}

\author{
Akemi J. Tanaka, ${ }^{1,7}$ Kanji Okumoto, ${ }^{2,3,7}$ Shigehiko Tamura, ${ }^{3,4,7}$ Yuichi Abe, ${ }^{5}$ \\ Yoel Hirsch, ${ }^{6}$ Liyong Deng, ${ }^{1}$ Joseph Ekstein, ${ }^{6}$ Wendy K. Chung, ${ }^{1}$ and Yukio Fujiki ${ }^{5}$ \\ ${ }^{1}$ Department of Pediatrics, Columbia University Medical Center, New York, New York 10019, USA; \\ ${ }^{2}$ Department of Biology, Faculty of Sciences, ${ }^{3}$ Graduate School of Systems Life Sciences, ${ }^{4}$ Faculty of Arts and \\ Science, ${ }^{5}$ Division of Organelle Homeostasis, Medical Institute of Bioregulation, Kyushu University, Fukuoka \\ 812-8582, Japan; 'Dor Yeshorim, The Committee for Prevention of Jewish Genetic Diseases, Brooklyn, \\ New York 11211, USA
}

Corresponding author: yfujiki@kyudai.jp

(C) 2019 Tanaka et al. This article is distributed under the terms of the Creative Commons Attribution-NonCommercial License, which permits reuse and redistribution, except for commercial purposes, provided that the original author and source are credited.

Ontology terms: sensorineural hearing impairment; very long chain fatty acid accumulation

Published by Cold Spring Harbor Laboratory Press

doi:10.1101/mcs.a003483
Abstract Using clinical exome sequencing (ES), we identified an autosomal recessive missense variant, c.153C>A (p.F51L), in the peroxisome biogenesis factor 26 gene (PEX26) in a 19-yr-old female of Ashkenazi Jewish descent who was referred for moderate to severe hearing loss. The proband and three affected siblings are all homozygous for the c.153C>A variant. Skin fibroblasts from this patient show normal morphology in immunostaining of matrix proteins, although the level of catalase was elevated. Import rate of matrix proteins was significantly decreased in the patient-derived fibroblasts. Binding of Pex26-F51L to the AAA ATPase peroxins, Pex1 and Pex6, is severely impaired and affects peroxisome assembly. Moreover, Pex26 in the patient's fibroblasts is reduced to $30 \%$ of the control, suggesting that Pex26-F51L is unstable in cells. In the patient's fibroblasts, peroxisome-targeting signal 1 (PTS1) proteins, PTS2 protein 3-ketoacyl-CoA thiolase, and catalase are present in a punctate staining pattern at $37^{\circ} \mathrm{C}$ and in a diffuse pattern at $42^{\circ} \mathrm{C}$, suggesting that these matrix proteins are not imported to peroxisomes in a temperature-sensitive manner. Analysis of peroxisomal metabolism in the patient's fibroblasts showed that the level of docosahexaenoic acid (DHA) (C22:6n-3) in ether phospholipids is decreased, whereas other lipid metabolism, including peroxisomal fatty acid $\beta$-oxidation, is normal. Collectively, the functional data support the mild phenotype of nonsyndromic hearing loss in patients harboring the F51L variant in PEX26.

[Supplemental material is available for this article.]

\section{INTRODUCTION}

Peroxisomes are single membrane-bounded organelles that function in numerous metabolic pathways, including $\beta$-oxidation of very long-chain fatty acids (VLCFA), detoxification of hydrogen peroxides, and synthesis of ether phospholipids and bile acids (Wanders and Waterham 2006). Impairment of peroxisome biogenesis causes peroxisome biogenesis disorders (PBDs), termed Zellweger spectrum disorders (ZSDs), including Zellweger syndrome (ZS), neonatal adrenoleukodystrophy (NALD), and infantile Refsum disease (IRD), and rhizomelic chondrodysplasia punctata types 1 and 5 (Gould and Valle 2000; Fujiki et al. 2006; Barøy et al. 2015). Fourteen PEX genes, including peroxisome biogenesis factor 26

${ }^{7}$ A.J.T., K.O., and S.T. equally contributed to this work. 
COLD SPRING HARBOR Molecular Case Studies
New mutation of PEX26 causing only hearing loss
(PEX26), have been identified as the causes of PBDs (Waterham and Ebberink 2012; Fujiki et al. 2014; Fujiki 2016).

The PEX26 gene (OMIM\# 608666) encodes the peroxisome assembly factor termed peroxin Pex26, which is involved in peroxisomal matrix protein import (Matsumoto et al. 2003a). Biallelic pathogenic variants in the PEX26 gene are associated with ZSDs of complementation group (CG) 8 , which have variable clinical manifestations ranging from a severe, lethal phenotype in ZS to NALD (PBD7A; OMIM\# 615872), and the least severe IRD (PBD7B; OMIM\# 614873). Patients with ZS have significant hypotonia with poor feeding, distinctive facial features, seizures, and hepatic dysfunction and typically do not live past the first year of life. Older children with ZS show significant developmental delay with retinal dystrophy and sensorineural hearing loss. The phenotypes of NALD and IRD are variable and milder than ZS and may include developmental delay, hypotonia, hearing loss, visual impairment, hemorrhage, and intracranial bleeding. Pathogenic variants in PEX26 have been identified in patients with ZSD (Supplemental Table S1; Matsumoto et al. 2003a,b; Steinberg et al. 2004, 2006; Weller et al. 2005; Furuki et al. 2006; Ebberink et al. 2011; Neuhaus et al. 2017; Stowe and Agarwal 2017). Here, we describe an Ashkenazi Jewish family with four affected individuals who are all homozygous for a predicted deleterious missense variant in PEX26 and who all share a phenotype of nonsyndromic sensorineural hearing loss with no other symptoms of ZSD.

\section{RESULTS}

\section{Clinical Presentation and Family History}

The proband is a 19-yr-old female who was referred for moderate to severe hearing loss and a family history significant for three siblings with hearing loss. The proband and affected siblings are otherwise healthy, and all had normal prenatal and postnatal clinical courses and neurodevelopment.

Clinical exome sequencing (ES) was performed at GeneDx (Gaithersburg, MD, USA) (Supplemental Table S2) as previously described (Tanaka et al. 2017) on the proband (Fig. $1 \mathrm{~A}$, Individual 3), both parents, and one affected sibling (Individual 1) from a family with four affected individuals with nonsyndromic hearing loss and three unaffected siblings (Individuals 2, 4, and 7). An autosomal recessive missense variant in PEX26 was identified as potentially causative for the nonsyndromic hearing loss phenotype (Table 1). The c. 153C >A (F51L) variant in the PEX26 gene (Fig. 1B) was confirmed by Sanger sequencing to be homozygous in the proband and the affected sibling and heterozygous in each parent (Fig. 1C, left panels; Table 2). The mutation was also identified by reverse transcription (RT)PCR product using poly(A) ${ }^{+}$RNA from fibroblasts of the proband (Individual 3), termed Pex26-F51L (Fig. 1C, right panels). The proband's affected younger brother (Individual 6) and sister (Individual 5) were analyzed only for the c.153C>A PEX26 variant and were homozygous for the A allele. The genotypes for the unaffected siblings are shown in Figure 1.

The F51 L variant is located in a highly evolutionarily conserved region across species (Fig. $1 \mathrm{D}, \mathrm{E})$ and is predicted to be deleterious by SIFT (http://sift.jcvi.org/), Provean (http://provean .jcvi.org/), CADD (http://cadd.gs.washington.edu/), and MetaSVM (https://omictools.com/ meta-svm-tool) (Table 3). In our earlier report, we demonstrated that the region of Pex26 protein encompassing residues 12-77 and 78-85 in the amino-terminal region is involved in the interaction with the Pex1-Pex6 complex and Pex14, respectively (Fig. 1B; Tamura et al. 2014). The F51L variant is a rare missense variant that occurs at low frequency in the Genome Aggregation Databases (gnomAD) (allele frequency $=2.239 \times 10^{-5}, 4 / 178,684$ total individuals) and is absent in the gnomAD genomes and NHLBI Exome Variant Server (EVS) databases, indicating that it is not a common variant in the populations represented 
A I.

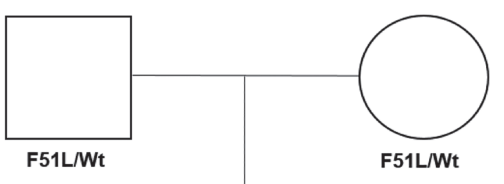

II.

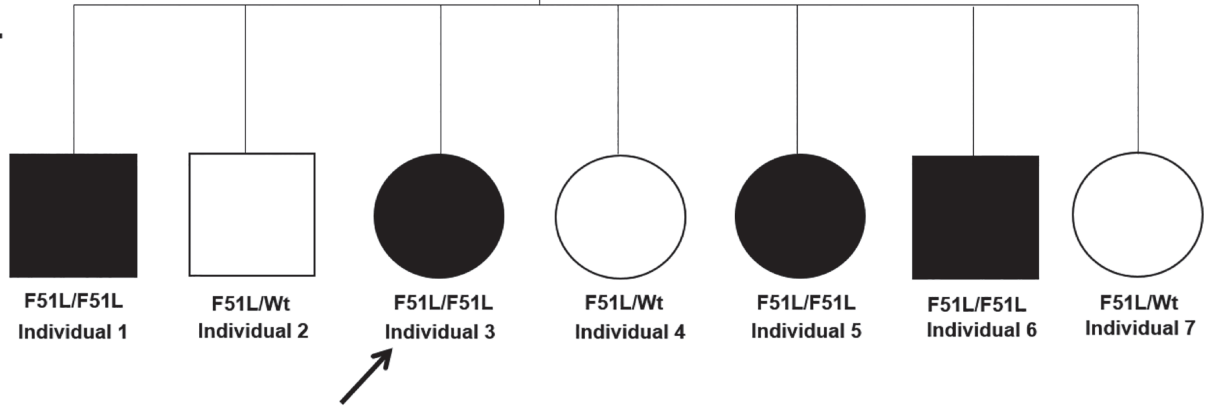

B Binding to Pex6

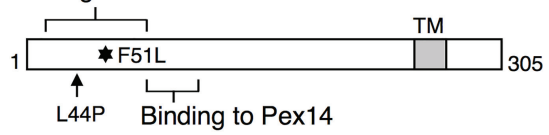

C Control (sibling) 49 Leu Asp Phe Arg Ala 53 C T G G AC T T C C G G G C G

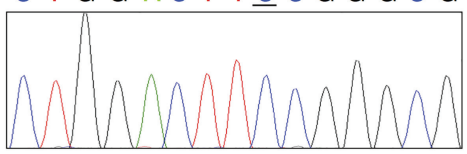

\section{Heterozygous sibling}
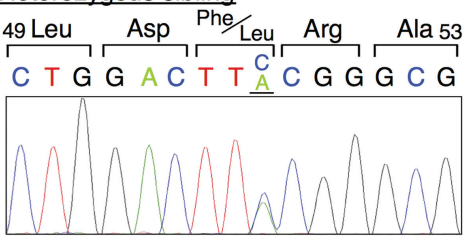

Pex26-F51L

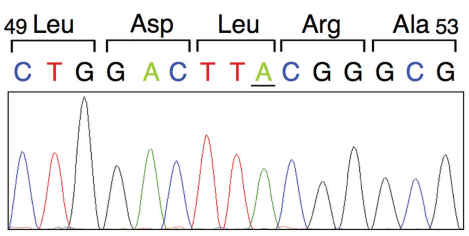

Control

49 Leu Asp Phe Arg Ala 53

C T G G A C T T $\underline{C} \mathrm{C} G \mathrm{GGCG}$

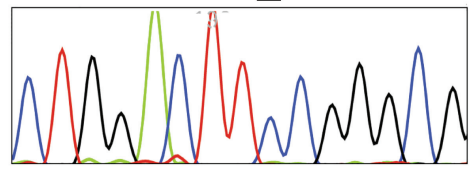

$\downarrow$

Pex26-F51L

49 Leu Asp, Leu Arg Ala 53

C T G G A C T TACG G G C G

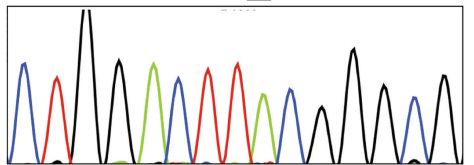

Figure 1. Mutation analysis of PEX26 from individuals with nonsyndromic hearing loss. (A) Pedigree of a family with F51 L mutation in PEX26. The affected proband (arrow) is homozygous for the F51 L mutation. (B) Schematic representation of human Pex26. (Numbers) amino acid residues of Pex26, (*) F51L mutation identified in $A$, (shaded box) transmembrane segment; the regions at 12-77 and 78-85 in the amino-terminal region interact with the Pex1-Pex6 complex and Pex14, respectively. (C) Exome sequencing analysis identified one point mutation of nucleotide $\mathrm{C} 153$ (the $A$ of the initiator ATG being no. 1) in the codon for Phe51 to $A$ in the PEX26 gene. (Left) Sanger electropherograms of control, heterozygous, and homozygous siblings are shown. (Right) Mutation analysis was also performed by RT-PCR, in which the mutation of nucleotide C153 to A resulting in F51L was detected in Pex26-F51L fibroblasts. (Figure and legend continue on following page.) 


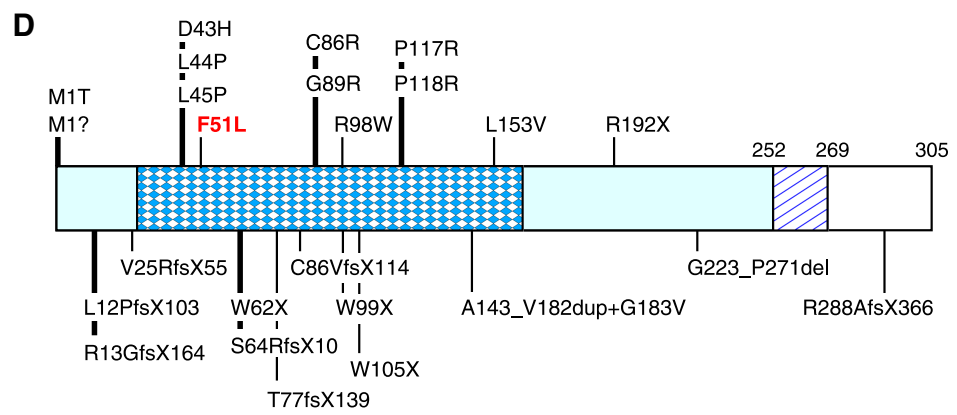

E

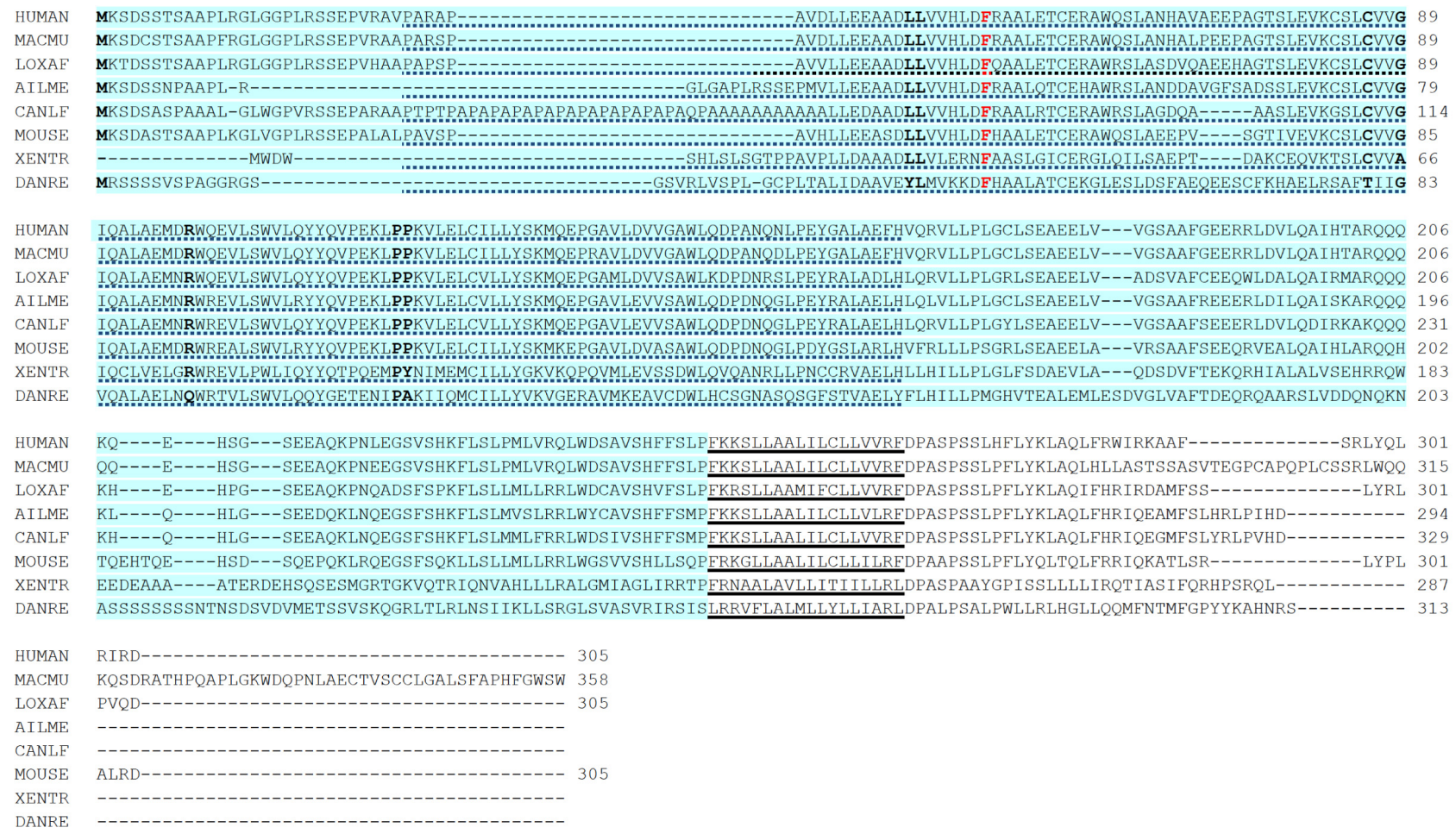

Figure 1. (Continued.) (D) Human mutations in Pex26. Previously identified mutations in Pex26 are marked with missense and nonsense mutations above the protein diagram, and frameshift, truncating, and copy-number variation (CNV) mutations below. (Blue) cytoplasmic domain, (diamonds) other peroxin-interacting domain, (striped lines) transmembrane domains. (E) Pex26 sequence alignment. Characteristics of Pex26 are from human studies. Missense mutations are in bold, F51 L in red. (Blue highlight) Cytoplasmic domains, (dotted underline) other peroxin-interacting domains, (single underline) transmembrane domains. (Macmu) Rhesus macaque, (Loxaf) elephant, (Ailme) giant panda, (Canlf) dog, (Xentr) Xenopus tropicalis, (Danre) zebrafish.

\begin{tabular}{|c|c|c|c|c|c|c|c|c|c|}
\hline Gene & Chromosome & $\begin{array}{l}\text { HGVS DNA } \\
\text { reference }\end{array}$ & $\begin{array}{l}\text { HGVS protein } \\
\text { reference }\end{array}$ & Variant type & $\begin{array}{c}\text { Predicted effect } \\
\text { (substitution, } \\
\text { deletion, etc.) }\end{array}$ & $\begin{array}{l}\text { dbSNP/ } \\
\text { dbVar ID }\end{array}$ & $\begin{array}{c}\text { Genotype } \\
\text { (heterozygous/ } \\
\text { homozygous) }\end{array}$ & ClinVar ID & $\begin{array}{l}\text { Parent } \\
\text { of origin }\end{array}$ \\
\hline PEX26 & 22 & $\begin{array}{l}\text { NM_017929.5: } \\
\text { c.153C>A }\end{array}$ & $\begin{array}{l}\text { NP_060399.1: } \\
\text { p.Phe51Leu }\end{array}$ & $\begin{array}{l}\text { Single-nucleotide } \\
\text { variant }\end{array}$ & Substitution & rs777633990 & Homozygous & SCV000804559 & Biparental \\
\hline
\end{tabular}


Table 2. Clinical phenotype of PEX26 F51L variant in four affected individuals

\begin{tabular}{|c|c|c|c|c|c|c|c|c|c|}
\hline Individual & Sex & Age & $\begin{array}{l}\text { Prenatal } \\
\text { issues }\end{array}$ & $\begin{array}{l}\text { Newborn } \\
\text { screening }\end{array}$ & Type of hearing loss & Age of onset & Laterality & $\begin{array}{l}\text { Degree and } \\
\text { configuration }\end{array}$ & Other medical \\
\hline 1 & M & 24 & None & Negative & SNHL, mild & $2-3 y r$ & Bilateral & Symmetric & None \\
\hline 3 & $\mathrm{~F}$ & 18 & None & Negative & SNHL, moderate to severe & $12-24 \mathrm{mo}$ & Bilateral & Symmetric & None \\
\hline 5 & $\mathrm{~F}$ & 19 & None & Negative & $\mathrm{SNHL}$, moderate to severe & $12-24 \mathrm{mo}$ & Bilateral & Symmetric & None \\
\hline 6 & M & 12 & None & Negative & $\mathrm{SNHL}$, moderate to severe & $12-24 \mathrm{mo}$ & Bilateral & Symmetric & None \\
\hline
\end{tabular}

(SNHL) Sensorineural hearing loss.

by these databases. The four individuals identified in gnomAD exomes heterozygous for the F51L variant are of Ashkenazi Jewish (AJ) descent, and F51 L appears to be a founder mutation with an estimated carrier frequency of 1/1878 in the AJ population (https://ibd .broadinstitute.org/).

\section{Peroxisomal Protein Import Is Morphologically Normal in Pex26-F51L Fibroblasts}

Using immunofluorescence microscopy of control fibroblasts, catalase (Fig. 2A) as well as peroxisome-targeting signal 1 (PTS1) proteins including acyl-CoA oxidase (AOx) and a peroxisome-targeting signal 2 (PTS2) protein, alkyldihydroxyacetonephosphate synthase (ADAPS), were detected in punctate structures that merged with Pex14 (Fig. 2B), showing normal import of both PTS1 and PTS2 types of matrix proteins into peroxisomes. Earlier reports showed that fibroblasts derived from CG8 patients with ZS and with NALD and IRD demonstrate complete and partial defects in peroxisomal import of catalase and a PTS2 protein, 3ketoacyl-CoA thiolase (TH), respectively, although PTS1 proteins were similarly discernible in peroxisomes as in control fibroblasts and those from CG8 patients with ZS, NALD, and IRD (Matsumoto et al. 2003b; Furuki et al. 2006). In Pex26-F51 L fibroblasts, peroxisomal localization of catalase was observed (Fig. 2D-F) similar to control fibroblasts (Fig. 2A-C). PTS1 proteins (Fig. 2G-I), AOx (Fig. 2J-L) and ADAPS (Fig. 2M-O) were likewise localized to peroxisomes in fibroblasts from the proband as in control fibroblasts. These results suggest the biochemical phenotype is milder compared to that reported in CG8 fibroblasts associated with NALD and IRD, showing little to no detectable defect in peroxisomal matrix protein import as assessed by morphological analysis.

\section{Unstable Pex26 in Pex26-F51L Fibroblasts Affects Catalase Protein Level and Intracellular Distribution}

Next, peroxisome biogenesis in Pex26-F51L fibroblasts was investigated by immunoblot analysis. In mammals, several PTS1 proteins such as a $75-\mathrm{kDa}$ polypeptide A-chain of full-length $\mathrm{AOx}$ and a precursor form of sterol carrier protein $\mathrm{x}(\mathrm{SCPx})$, are proteolytically processed in the peroxisomal matrix, resulting in $53-k D a$ B-chain and $22-k D a$ C-chain

\begin{tabular}{|c|c|c|c|c|c|c|c|c|c|c|c|}
\hline Gene & Chromosome & $\begin{array}{l}\text { Chromosome } \\
\text { coordinates } \\
\text { (GRCh37/hg19) }\end{array}$ & Transcript & $\begin{array}{l}\text { Nucleotide } \\
\text { change }\end{array}$ & $\begin{array}{l}\text { Amino acid } \\
\text { change }\end{array}$ & SIFT & Provean & PolyPhen-2 & MetaSVM & CADD13 & $\begin{array}{l}\text { Allele frequency } \\
\text { in gnom } A D\end{array}$ \\
\hline PEX26 & 22 & 18561295 & $\begin{array}{l}\text { PEX26: } \\
\text { NM_017929.5 }\end{array}$ & c. $153 C>A$ & p.Phe51Leu & $\begin{array}{l}\text { Damaging } \\
(0.00)\end{array}$ & $\begin{array}{c}\text { Damaging } \\
(-4.56)\end{array}$ & $\begin{array}{l}\text { Probably damaging } \\
\text { (0.999) }\end{array}$ & $\begin{array}{r}\text { Damaging } \\
(0.4751)\end{array}$ & 23.0 & $0.00002239^{a}$ \\
\hline
\end{tabular}

a 4/178684, no homozygotes, mean exomes coverage $53.7 \times$. 


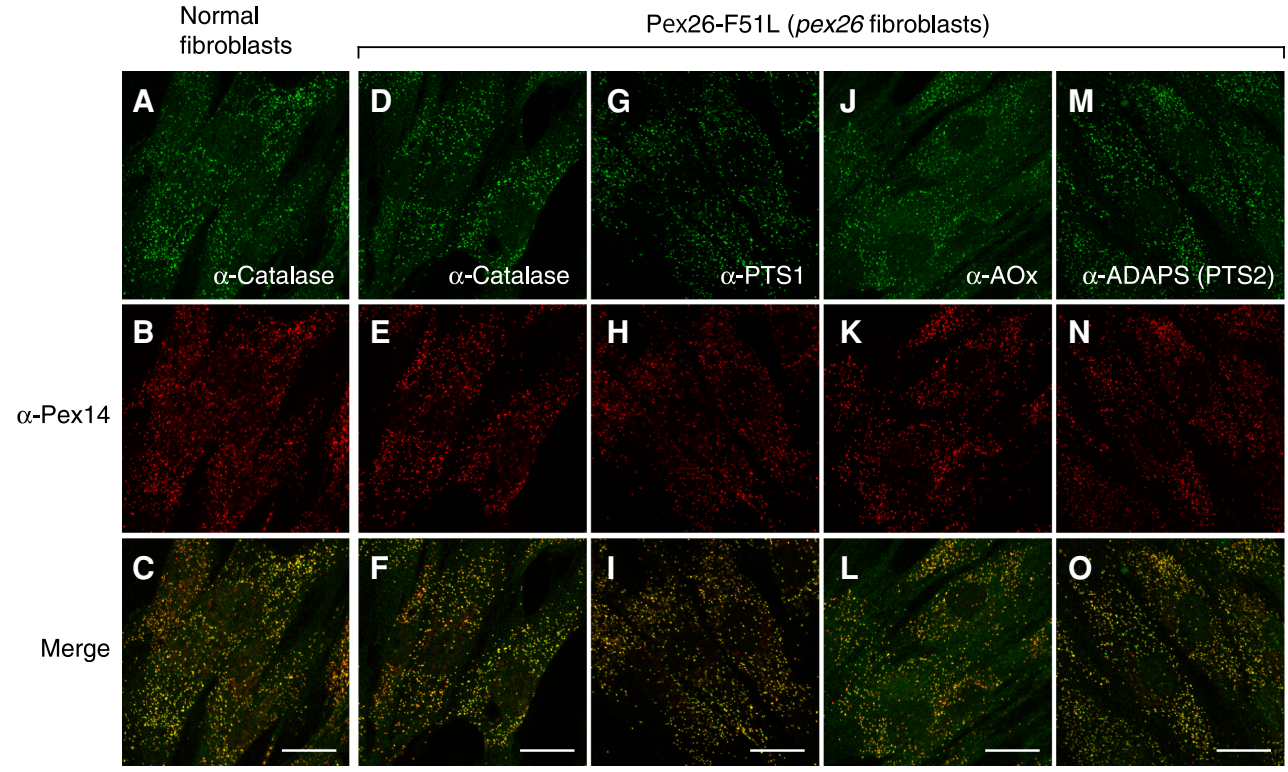

Figure 2. Morphological analysis of fibroblasts derived from a patient with PEX26 mutation. Control fibroblasts $(A-C)$ and Pex26-F51L fibroblasts from a PEX26-defective patient $(D-O)$ were immunostained with antibodies to Pex14 $(B, E, H, K, N)$ and peroxisomal matrix proteins indicated in top panels $(A, D, G, J, M)$. Merged views are shown in bottom panels $(C, F, I, L, O)$. (AOx) Acyl-CoA oxidase, (ADAPS) alkyl-dihydroxyacetonephosphate synthase. Scale bar, $10 \mu \mathrm{m}$.

components of $\mathrm{AOx}$ and a mature form of SCPx, respectively (Miyazawa et al. 1989; Shimozawa et al. 1992; Otera et al. 2001). Processing of AOx and SCPx was observed to a similar extent in both control fibroblasts and Pex26-F51L cells (Fig. 3A, left panels). Protein levels of other PTS1 proteins, dihydroxyacetonephosphate acyltransferase (DHAPAT) and peroxisomal Lon protease (PsLon), were also indistinguishable between control fibroblasts and Pex26-F51L fibroblasts (Fig. 3A, left panels). Precursors of PTS2 proteins, TH and ADAPS, are converted to their respective mature forms by cleaving the amino-terminal PTS2 presequences in peroxisomes (Osumi et al. 1991; Swinkels et al. 1991; de Vet et al. 1998; Honsho et al. 2008). Only mature forms of TH and ADAPS were likewise discernible in both control fibroblasts and Pex26-F51L fibroblasts (Fig. 3A). These phenotypes correlated well with the observation that full-length trypsin domain-containing 1 (Tysnd1), the enzymatically active form of a PTS1 protein catalyzing both processing of PTS1 proteins and cleavage of PTS2 proteins (Kurochkin et al. 2007; Okumoto et al. 2011), was detectable at a similar level in both control and Pex26-F51L fibroblasts (Fig. $3 \mathrm{~A}$, right panels). These results strongly suggest that peroxisomal matrix protein import, including both PTS1 and PTS2 proteins, is largely normal in Pex26-F51L fibroblasts, consistent with cell-immunostaining analysis (Fig. 2).

Furthermore, there was no difference between Pex26-F51L fibroblasts and control fibroblasts in the expression of peroxisomal membrane proteins (PMPs) such as PMP70, peroxins Pex14 and Pex13, and fatty acyl-CoA reductase 1 (Far1) (Fig. 3A), indicative of the normal import of PMPs in the proband. Interestingly, we noted that catalase was significantly elevated in Pex26-F51L fibroblasts (Fig. 3A). Moreover, Pex26 protein levels were reduced to $30 \%$ of control fibroblasts as quantified by densitometry (Fig. 3B), suggesting that the c.153C $>$ A mutation in PEX26 reduces the stability of Pex26. It is possible that the instability of Pex26 in Pex26-F51L fibroblasts causes a mild phenotype representing morphologically undetectable defects in peroxisome biogenesis including normal peroxisomal protein import. 
COLD SPRING HARBOR Molecular Case Studies

New mutation of PEX26 causing only hearing loss

A

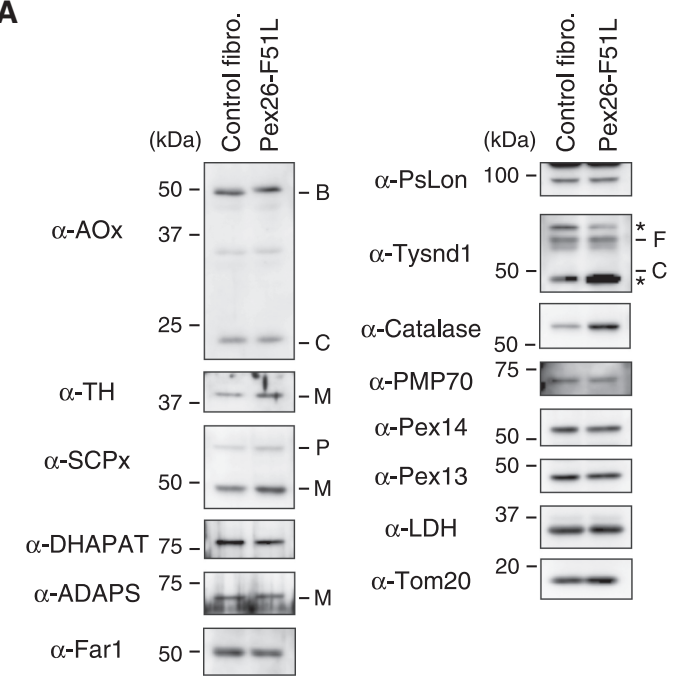

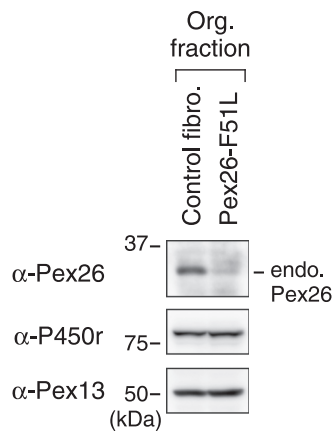

Figure 3. Biogenesis of peroxisomes in fibroblasts derived from a patient with defective PEX26. (A) Wholecell lysates of control fibroblasts and patient-derived PEX26-deficient fibroblasts (Pex26-F51L) were analyzed by SDS-PAGE and immunoblotting with antibodies indicated on the left. $B$ and $C$ in immunoblot with antiAOx antibody indicate $\mathrm{B}$ - and $\mathrm{C}$-chains derived from intraperoxisomal processing of the full-length A-chain, respectively. $\mathrm{F}$ and $\mathrm{C}$ in immunoblot with anti-Tysnd1 antibody show the full-length and the self-cleaved, carboxy-terminal portion of Tysnd1, respectively. ( $P$ and $M)$ Precursor and mature forms, respectively. Stars show nonspecific bands. (B) Protein level of endogenous Pex26 in Pex26-F51L fibroblasts. Organelle fractions prepared from postnuclear fraction of control fibroblasts and Pex26-F51L fibroblasts were analyzed by SDS-PAGE and immunoblotting with antibodies to Pex26 and an ER membrane protein P450 reductase (P450r).

\section{Temperature-Sensitive Phenotype and Decreased Peroxisomal Protein Import in Pex26-F51L Cells}

In Pex26-F51 Libroblasts, catalase, typical PTS1 proteins including AOx, and a PTS2 protein ADAPS were observed as punctate-staining structures at $37^{\circ} \mathrm{C}$, indicative of localization in the peroxisome (Fig. 2). We reported previously that temperature-sensitive (ts) peroxisome assembly is responsible for the milder clinical phenotype of IRD (Matsumoto et al. 2003b). To assess the ts phenotypic property of Pex26-F51L, cells were cultured at $42^{\circ} \mathrm{C}$ for $5 \mathrm{~d}$. PTS1 proteins, $\mathrm{TH}$, and catalase were detected in a diffuse staining pattern, suggesting these matrix proteins were not imported to peroxisomes at $42^{\circ} \mathrm{C}(\mathrm{Fig} .4 \mathrm{~A})$. These findings suggest less efficient import of matrix proteins in Pex $26-\mathrm{F} 51 \mathrm{~L}$ cells at $42^{\circ} \mathrm{C}$, whereas endogenous matrix proteins were likely imported normally under normal culture condition at $37^{\circ} \mathrm{C}$. To determine whether the mutant forms of Pex26 were expressed in Pex26-F51 fibroblasts, immunoblot analysis was performed with organelle fractions from control and proband fibroblasts, with an anti-Pex26 antibody. A Pex26 band was detected in control cells and Pex26-F51L fibroblasts cultured at $37^{\circ} \mathrm{C}$, with a reduced amount in Pex26-F51L cells (Fig. 4B, lanes 1,3 ) as in Figure 3B. In Pex26-F51L fibroblasts cultured at $42^{\circ} \mathrm{C}$, the mutated protein was barely detectable (Fig. 4B, lanes 3,4). We assessed the efficiency of peroxisomal matrix protein import by expressing enhanced GFP (EGFP)-PTS1, PTS2-EGFP, and EGFP-catalase in normal control and proband fibroblasts. The peroxisomal import of newly synthesized EGFP-tagged proteins was significantly decreased in Pex26-F51L fibroblasts as compared to control cells (Fig. 5). These results show that the mutated Pex26 protein is less effective in the peroxisomal import of matrix proteins. 
A

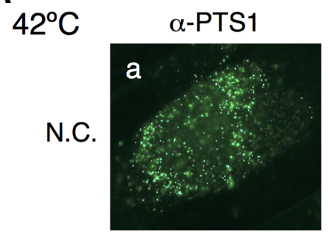

$\alpha-P T S 2$

thiolase

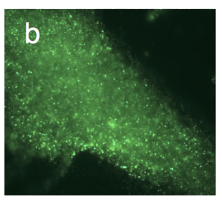

$\alpha$-catalase
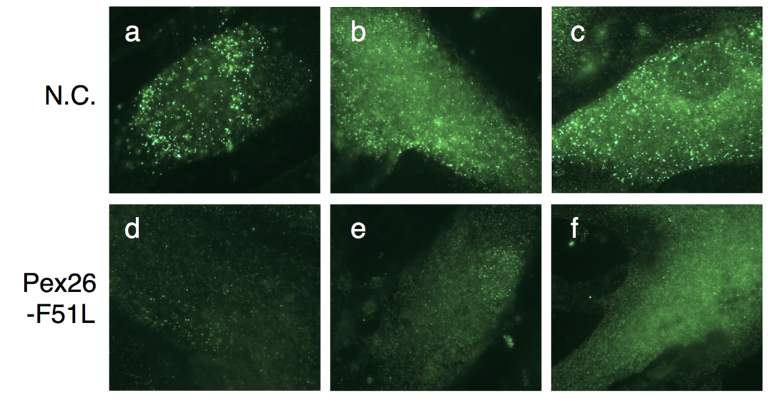

B

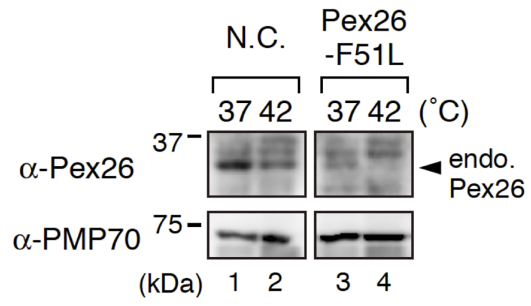

Figure 4. Characterization of Pex26-F51L fibroblasts. (A) Normal control (N.C.) and patient Pex26-F51L fibroblasts were cultured at $42^{\circ} \mathrm{C}$ for $5 \mathrm{~d}$ and then stained with antibodies to catalase ( $a$ and $\left.d\right), \operatorname{PTS} 1$ ( $b$ and $e$ ), and a PTS2 protein (thiolase) ( $c$ and f). Magnification, 630x. (B) Organelle fractions each of N.C. and Pex26-F51L fibroblasts were analyzed by SDS-PAGE and immunoblotting with antibodies to Pex26 and PMP70. The solid arrowhead indicates the position of endogenous Pex26.
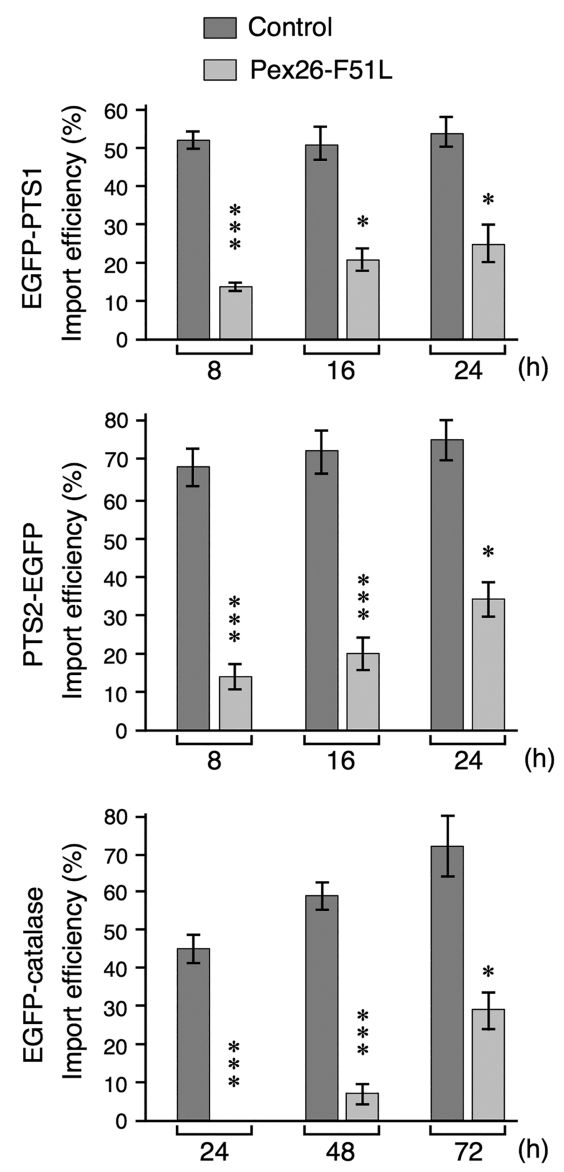

Figure 5. Transformation of Pex26-F51L fibroblasts with EGFP-fused PTS1, catalase, and PTS2 proteins. (Top) EGFPPTS1, (middle) PTS2-EGFP, and (bottom) EGFP-catalase were expressed in normal control and Pex26-F51L fibroblasts, respectively. Cells were cultured for the indicated time at $37^{\circ} \mathrm{C}$ and observed by EGFP fluorescence. The number of EGFP peroxisome-positive cells was counted in three separate areas. Data represent means $\pm \operatorname{SEM}(n=3) .\left(^{*}\right) P<0.05,\left({ }^{* * *}\right) P<$ 0.001 ; two-sided Welch's t-test. 
COLD SPRING HARBOR Molecular Case Studies
New mutation of PEX26 causing only hearing loss

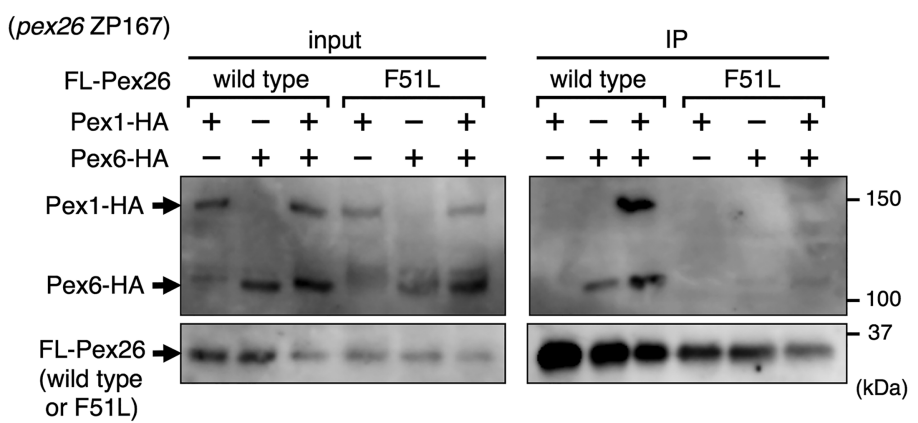

Figure 6. Binding to Pex 1 and Pex6 of patient-derived Pex26-F51L. pex26 CHO ZP167 cells were transfected with plasmids encoding Flag-Pex26 or Flag-Pex26-F51L identified in Pex26-F51L fibroblasts, together with those for Pex6-HA and Pex1-HA. Cells were then cultured at $30^{\circ} \mathrm{C}$ for $2 \mathrm{~d}$ (Matsumoto et al. 2003a). FlagPex26 and Flag-Pex26-F51 L were immunoprecipitated from cell lysates using anti-Flag antibody. Immunoprecipitates (IP) were analyzed by SDS-PAGE and immunoblotting with antibodies to HA and Flag. Input, 5\% input. (Upper panels) Arrows indicate Pex1-HA and Pex6-HA; (lower panels) arrow indicates the migration of Flag-Pex26.

\section{Pex26-F51L Interacts Less with Pex1-Pex6 Complexes}

We previously demonstrated that Pex26 interacts with Pex1-Pex6 complexes in a Pex6dependent manner (Tamura et al. 2014). To determine whether Pex26-F51L affects the interaction with Pex1-Pex6 complexes, we expressed Flag-tagged Pex26-F51L together with Pex1-HA and Pex6-HA in CHO pex26 ZP167 cells. ZP167 shows no matrix protein import but with detectable membrane remnants (Ghaedi et al. 1999; Matsumoto et al. 2003b). No transcript for PEX26 was detected (Y Fujiki, unpubl. data). Flag-Pex26-F51L was expressed at a lower level than wild-type Flag-Pex26 (Fig. 6), consistent with the expression level of endogenous Pex26 in control fibroblasts and mutant protein in Pex26-F51L fibroblasts. Flag-Pex26 and Flag-Pex26-F51L were immunoprecipitated from cell lysates using anti-Flag antibody-conjugated agarose beads and were analyzed by SDS-PAGE and immunoblotting with antibodies to Flag and HA. Pex1-HA and Pex6-HA were detected in the immunoprecipitates of normal Flag-Pex26, consistent with our earlier observation that Pex1-HA and Pex6-HA were co-immunoprecipitated with Flag-Pex26. Pex1-HA and Pex6$\mathrm{HA}$ were only barely discernible in the immunoprecipitates of mutant Flag-Pex26-F51L, indicating that the mutant protein less efficiently recruits the Pex1-Pex6 complexes to peroxisomes (Fig. 6, right panel).

\section{Docosahexaenoic Acid (DHA) Levels Were Decreased in Plasmalogens in Fibroblasts from Patient with PEX26 Mutations}

Severe defects of peroxisome biogenesis in skin fibroblasts from patients with ZS cause abnormal peroxisomal metabolism, including marked reduction of plasmalogens, accumulation of VLCFA, and reduction of DHA (Wanders 2004). To investigate whether the milder defect of peroxisome biogenesis in Pex26-F51L fibroblasts affects peroxisomal metabolisms, phospholipid compositions from control and Pex26-F51L fibroblasts were analyzed by liquid chromatography connected to tandem mass spectrometry (LC-MS/MS). Total amounts of ethanolamine plasmalogens (plasmenylethanolamine, PlsEtn) and VLCFA-containing phosphatidylcholine were not altered in Pex26-F51L cells (Fig. 7A,B). Degradation activity by $\beta$-oxidation of lignoceric acid (C24:0) in Pex26-F51 L fibroblasts was approximately at the same level as that in control cells (Fig. 7C), suggesting that peroxisomal fatty acid $\beta$-oxidation activity is not affected in Pex26-F51L fibroblasts. 
COLD SPRING HARBOR Molecular Case Studies
New mutation of PEX26 causing only hearing loss
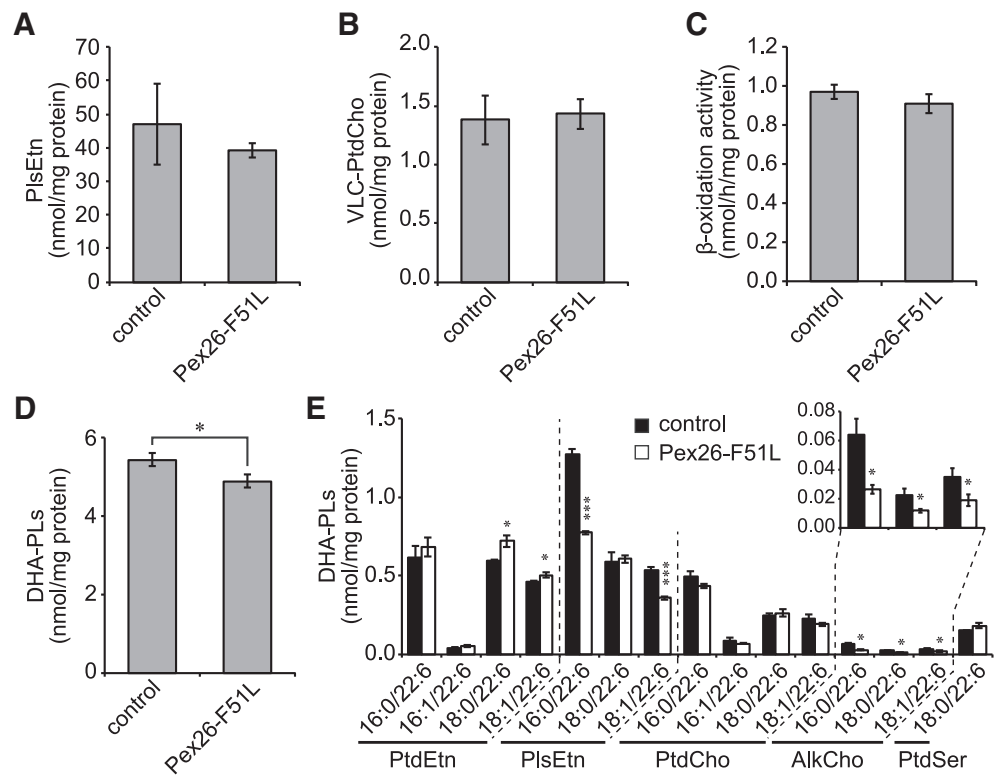

Figure 7. DHA-containing ether phospholipids are reduced in Pex26-F51 L fibroblasts. Cellular levels of PlsEtn (A) and VLCFA-containing phosphatidylcholine (VLC-PtdCho) (B) in control and Pex26-F51L fibroblasts were analyzed by LC-MS/MS. Data represent means \pm SEM $(n=7)$. (C) Peroxisomal VLCFA $\beta$-oxidation activities in control and Pex26-F51 L fibroblasts were assessed with ${ }^{14} \mathrm{C}$-lignoceric acid (C24:0) as substrate. Data represent means \pm SD of three independent experiments. Total amounts (D) and compositions (E) of DHA-PLs in fibroblasts were detected by LC-MS/MS. Data represented means \pm SEM $(n=7)$. (PtdSer) Phosphatidylserine. (*) $P<0.05$, (***) $P<0.001$; two-sided Welch's t-test.

Synthesis of DHA is initiated at the endoplasmic reticulum and completed by peroxisomal $\beta$-oxidation (Weller et al. 2003). Defects of peroxisomal biogenesis reduce DHA-containing phospholipids (DHA-PLs) as observed in fibroblasts from patients with ZS (Abe et al. 2014). LC-MS/MS analysis revealed that the total amount of DHA-PLs was slightly reduced in Pex26-F51L fibroblasts (Fig. 7D), owing to the decrease in DHA-containing ether phospholipids including PlsEtn, which is the most abundant DHA-PL in control fibroblasts, and plasmanylcholine (Fig. 7E). On the contrary, DHA-phosphatidylethanolamine was slightly elevated but DHA-phosphatidylcholine was not affected (Fig. 7E). Collectively, these results demonstrate that peroxisomal metabolism is functionally intact in Pex26-F51L cells except for the decrease of DHA in ether phospholipids.

\section{DISCUSSION}

Here, we report a novel role for PEX26 in a cell line from a family with an autosomal recessive, nonsyndromic form of hearing loss. By using ES, we identified a family of four affected individuals with nonsyndromic sensorineural hearing loss, who are homozygous for the novel missense variant, c. 153C >A (F51L), in PEX26. We have shown with functional cellular assays and biochemical analyses that the F51 L mutation confers a previously undescribed mild cellular phenotype of morphologically normal but defective peroxisome biogenesis, including decreased peroxisomal protein import.

We analyzed patient-derived Pex26-F51L fibroblasts by immunocytochemistry and the "temperature sensitivity" assay to determine the effect of the F51L mutation on Pex26 protein function. Earlier studies on patient-derived fibroblasts have demonstrated the 
COLD SPRING HARBOR Molecular Case Studies
New mutation of PEX26 causing only hearing loss association between PEX26 mutations found in patients with a clinically milder phenotype and the ts cellular phenotype that results from these mutations (Steinberg et al. 2006). In general, fibroblasts from patients with mild ZSD disease have a ts phenotype, whereas fibroblasts with PEX26 mutations causing the severe ZS clinical phenotype are not ts. Previous experiments on cell lines with pathogenic missense variants in PEX genes have shown that PEX-deficient fibroblasts incubated at $37^{\circ} \mathrm{C}$ produce a more severe cellular phenotype based on PTS1 and PTS2 import than when cultured at $30^{\circ} \mathrm{C}$ (Fujiki 2003; Fujiki et al. 2014). The lower temperature is presumed to allow the mutated protein to attain a more relaxed conformation, which enhances its function, whereas culture conditions at higher temperatures exacerbates the defect in cells yielding a milder import phenotype (Steinberg et al. 2006).

We thus characterized the effect of the F51L mutation on Pex26 function by incubating Pex $26-\mathrm{F} 51 \mathrm{~L}$ cells at $30^{\circ} \mathrm{C}, 37^{\circ} \mathrm{C}$, and $42^{\circ} \mathrm{C}$ and quantifying peroxisomal import of matrix proteins at each temperature. On initial examination of cells cultured at $37^{\circ} \mathrm{C}$, peroxisomal import of matrix proteins, including PTS1 and PTS2, and expression of PMPs by Pex26-F51L cells appeared normal and showed no difference from control fibroblasts cultured at $37^{\circ} \mathrm{C}$ (Fig. 2). However, at $42^{\circ} \mathrm{C}$, Pex26-F51L cells exhibited significantly delayed and decreased peroxisomal assembly and matrix protein import as compared to wild-type control fibroblasts (Fig. 4A), indicating destabilization of Pex26 protein activity. Interestingly, we noted that although catalase levels were significantly elevated in Pex26-F51 L cells (Fig. 3A), the total amount of Pex26 protein was reduced to $~ 30 \%$ as compared to control fibroblasts (Fig. 3B). This indicates that the mutated protein product in Pex26-F51L cells is unstable. Our results collectively show the F51 L mutation causes a very mild cellular phenotype representing morphologically normal but biochemically detectable defects in peroxisome biogenesis, including decreased peroxisomal protein import.

We further investigated the effect of the $\mathrm{F} 51 \mathrm{~L}$ mutation on peroxisomal metabolism by measuring peroxisomal fatty acid $\beta$-oxidation activity, plasmalogen biosynthesis, and DHA content. Patients with ZSDs show severe defects in peroxisome biogenesis, which results in abnormal peroxisomal metabolism, including marked reduction of PlsEtn, accumulation of VLCFA, and reduction of DHA (Wanders and Waterham 2006; Abe et al. 2014; Fujiki et al. 2014). The reduction of plasmalogens gives rise to the up-regulation of Far1 proteins, the rate-limiting enzyme of plasmalogen biosynthesis, in a manner dependent on cellular plasmalogen levels (Honsho et al. 2010). In fibroblasts from patients who carry defects in peroxisomal fatty acid $\beta$-oxidation, DHA contents are markedly reduced and peroxisomes are much less abundant than in wild-type cells. We previously found that DHA is a crucial signal for the morphogenesis of peroxisomes, and, moreover, treatment of $\beta$-oxidation-deficient fibroblasts with DHA induces peroxisomal proliferation (Itoyama et al. 2012). DHA treatment may therefore provide a therapeutic approach to stimulate peroxisome formation and ostensibly rescue peroxisomal $\beta$-oxidation activity in patients with PBD.

We therefore examined Far1 and DHA levels in Pex26-F51L cells and demonstrated that the F51 L mutation results in normal level of total plasmalogens and peroxisomal $\beta$-oxidation activity (Fig. 7A,C). But, of note, the levels of DHA in ether phospholipids (DHA-containing plasmalogens) were reduced (Fig. 7D), whereas DHA-phosphatidylethanolamine levels were slightly elevated (Fig. 7E). In control fibroblasts, components identified in DHA-PLs suggest DHA is preferentially incorporated into plasmalogens (Fig. 7E), although its underlying mechanism is not well understood. We have shown previously that in fibroblasts deficient in peroxisomal fatty acid $\beta$-oxidation, all classes of DHA-PLs are reduced (Itoyama et al. 2012). It is therefore plausible that the retarded peroxisomal import of matrix proteins exhibited by Pex26-F51L cells affects the biosynthesis of DHA-containing plasmalogens. The abnormal ratio of constituents in the DHA-ether lipids may also suggest the defect underlying the phenotype of hearing loss, whereas the causal mechanism is unclear. 
COLD SPRING HARBOR Molecular Case Studies
New mutation of PEX26 causing only hearing loss
Sensorineural hearing loss results from malfunction of inner ear structures, including the cochlea and auditory nerve. It would thus be necessary to study PEX26 expression and function in the sound sensing cells, such as the cochlear inner hair cells, from patient-derived cell lines or animal models of deafness. Deletion of the DNB40 locus on 22q11.21-12.1, which includes the PEX26 gene, has been previously associated with autosomal recessive sensorineural hearing loss (Delmaghani et al. 2003). Three otherwise healthy siblings with sensorineural hearing loss from a consanguineous Iranian family were identified to be homozygous for a 9-Mb deletion encompassing the 22q11.21-12.1 chromosome region, which contains more than 80 genes. Several of the genes in this region for which nonsyndromic and syndromic hearing impairment have been associated, including TBX1, DGCR6, and CRYBB1, were examined in additional families with a recessive form of hearing loss, but no mutations were detected in the coding regions of these genes (Delmaghani et al. 2003). A recent study by the same team of researchers reported decreased levels of peroxisomal biogenesis in the cochlear cells of Persian families with sensorineural hearing loss who harbor a specific mutation in the PJVK gene (Delmaghani et al. 2015). The PJVK gene encodes the gasdermin protein, pejvakin (PJVK), which is required for auditory neuronal function in vertebrates, and mutations in PJVK are known to cause autosomal recessive deafness 59 (OMIM\#610220). It is hypothesized that PJVK plays an essential role in regulating peroxisomal dynamics in mechanosensory hair cells of the inner ear (Delmaghani et al. 2015). It is thus possible that the F51L mutation in PEX26 from our patients' family may also predominantly affect the cells of the inner ear responsible for sensorineural hearing.

In summary, we have identified and characterized a novel variant in PEX26 from a family with nonsyndromic sensorineural hearing loss. The F51L missense variant in PEX26 causes a mild defect in peroxisome biogenesis, including decreased peroxisomal protein import and reduced levels of DHA-PLs. It remains to be determined how the F51L variant affecting the function and expression of PEX26 causes hearing loss. Testing of individuals with sensorineural hearing loss in AJ communities may help to identify more individuals with Pex26associated hearing loss and will allow us to elucidate the underlying molecular defect linking the $\mathrm{F} 51 \mathrm{~L}$ cellular phenotype to hearing loss in patients.

\section{METHODS}

Studies were approved by the Institutional Review Board of Columbia University.

\section{Exome Sequencing}

Genomic DNA was extracted from whole blood from the affected children and their parents. Exome sequencing at GeneDx was performed on exon targets captured using the Agilent SureSelect Human All Exon V4 (50 Mb) or the Clinical Research Exome kit (Agilent Technologies) according to the manufacturer's instructions. Libraries were sequenced using the Illumina HiSeq 2000 or 2500 sequencing system with 100-bp paired-end reads (Illumina). Whole-exome sequence data for all sequenced family members was analyzed using GeneDx's XomeAnalyzer (a variant annotation, filtering, and viewing interface for exome sequencing data) as described previously (Tanaka et al. 2017). The identified sequence variant of interest was confirmed in the proband, affected siblings, and both parents by conventional di-deoxy DNA sequence analysis using an ABI3730 (Life Technologies).

\section{RT-PCR}

Poly $(A)^{+}$RNA was obtained from fibroblasts from a proband with sensorineural hearing loss by a QuickPrep mRNA purification kit (Amersham Biosciences). RT-PCR of PEX26 was 
performed with a pair of forward primer $1 \mathrm{~F}$ ( $5^{\prime}$-AAGAGCGATTCTTCGACC- $3^{\prime}$ at amino acid residues 4-21 and reverse primer 1R (5'-GTCACGGATGCGGAGCTG-3' at 898-915 (Matsumoto et al. 2003a). PCR products were directly sequenced.

\section{Patient-Derived Cell Line}

Punch skin biopsy was performed on the proband to create a cell line for functional analysis.

\section{Cell Culture}

Control fibroblasts and Pex26-F51L fibroblasts were maintained in DMEM (Invitrogen), and a PEX26-deficient CHO cell mutant ZP167 (Matsumoto et al. 2003a) was maintained in Ham's F-12 medium (Invitrogen); both media were supplemented with 10\% FBS under conditions of $5 \% \mathrm{CO}_{2}, 95 \%$ air at $37^{\circ} \mathrm{C}$. For analysis of ts phenotype, fibroblasts were cultured for $5 \mathrm{~d}$ at $42^{\circ} \mathrm{C}$.

\section{Antibodies}

Rabbit antisera to catalase (Tsukamoto et al. 1990), PTS1 (Otera et al. 1998), AOx (Tsukamoto et al. 1990), ADAPS (Honsho et al. 2008), TH (Tsukamoto et al. 1990), SCPx (Otera et al. 2001), DHAPAT (Honsho et al. 2017), Far1 (Honsho et al. 2010), PsLon (Okumoto et al. 2011), Tysnd1 (Okumoto et al. 2011), PMP70 (Tsukamoto et al. 1990), Pex14 (Harano et al. 1999), Pex13 (Mukai and Fujiki 2006), and Pex26 (Matsumoto et al. 2003a) were used. Mouse monoclonal antibodies to the Flag epitope (M2; Sigma-Aldrich), influenza virus hemagglutinin (HA) (16B12; Covance), P450 reductase (F-10; Santa Cruz), and Tom20 (F-10; Santa Cruz) and goat antiserum to lactate dehydrogenase (Rockland) were purchased.

\section{Extraction of Phospholipid from Fibroblasts}

Fibroblasts plated in the six-well plate were dissociated by trypsin treatment and then suspended in PBS. Protein concentration of the cell suspension was determined by bicinchonic acid methods using a Pierce BCA protein assay kit (Thermo Fisher Scientific). Total lipids were extracted from $50 \mu \mathrm{g}$ of total cellular proteins by the Bligh and Dyer method (Bligh and Dyer 1959). Cells were suspended in methanol/chloroform/water at 2:1:0.8 (v/v/v) and then $50 \mathrm{pmol}$ of 1,2-didodecanoyl-sn-glycero-3-phosphocholine (DDPC, Avanti Polar Lipids) and 1,2-didodecanoyl-sn-glycero-3-phosphoethanolamine (DDPE, Avanti Polar Lipids) were added as internal standards. After incubation for $5 \mathrm{~min}$ at room temperature, $1 \mathrm{~mL}$ each of water and chloroform was added and the samples were then centrifuged at 2000 rpm for 5 min in Himac CF-16RX (Hitachi Koki) to collect the lower organic phase. To re-extract lipids from the water phase, $1 \mathrm{~mL}$ chloroform was added. Combined organic phase was evaporated under a nitrogen stream and the extracted lipids were dissolved in methanol.

\section{Liquid Chromatography Coupled with Tandem Mass Spectrometry (LC-MS/MS)}

LC-MS/MS was performed as described (Abe et al. 2014) using a 4000 Q-TRAP quadrupole linear ion trap hybrid mass spectrometer (AB Sciex) with an ACQUITY UPLC System (Waters). The data were analyzed and quantified using Analyst software version 1.42 (AB Sciex).

\section{Measurement of Fatty Acid $\beta$-Oxidation Activity}

Fatty acid $\beta$-oxidation activity was determined as described (Suzuki et al. 1991). Cells grown in six-well plates were preincubated for $1 \mathrm{~h}$ at $37^{\circ} \mathrm{C}$ in serum-free DMEM. After the medium was changed to fresh serum-free DMEM, $2 \mathrm{nmol}$ of ${ }^{14} \mathrm{C}-\mathrm{C} 24: 0$ (American Radiolabeled Chemicals) in $0.1 \mathrm{M}$ Tris- $\mathrm{HCl}, \mathrm{pH} 8.0$, containing $10 \mathrm{mM}$ a-cyclodextrin was added to the culture medium, and cells were further incubated for $2 \mathrm{~h}$ at $37^{\circ} \mathrm{C}$. The radioactivity of 
COLD SPRING HARBOR Molecular Case Studies
New mutation of PEX26 causing only hearing loss
Competing Interest Statement

The authors have declared no competing interest.

Received August 24, 2018; accepted in revised form November 2, 2018. acid-soluble metabolites was measured using an AccuFLEX LSC-8000 (Hitachi). Fatty acid $\beta$ oxidation activity was calculated as $\mathrm{nmol} / \mathrm{h} / \mathrm{mg}$ of protein.

\section{Other Methods}

Immunoblotting and immunofluorescence microscopy were performed as described (Hosoi et al. 2017).

\section{ADDITIONAL INFORMATION}

\section{Data Deposition and Access}

Whole-exome sequencing data are not publicly available because patient consent could not be obtained. The PEX26 variant found in this study has been deposited in ClinVar (https:// urldefense.proofpoint.com/v2/url?u=http-3A_www.ncbi.nlm.nih.gov_clinvar_\&d=DwICJg \&c=mkpgQs82XaCKIwNV8b32dmVOmERqJe4bBOtF0CetP9Y\&r=OVgK9N-fohjgKXCkC0 sSYQ\&m=0R7rL3r5MeZgk1YPetn3FofhMnnojEOrVN7TTJtyfcg\&s=iHLSL53bxvs_xveEcnjiK hAgv-wrsDoprnldboINBpc\&e=) under accession number SCV000804559.

\section{Ethics Statement}

The study was approved by the Institutional Review Board of Columbia University. Written informed consent was obtained from the probands or proband's siblings and parents for publication.

\section{Acknowledgments}

We thank M. Ishii for preparing figures and the other members of Fujiki laboratory for discussions. This work was supported in part by Grants-in-Aid for Scientific Research JP26116007, JP15K21743 and JP17H03675 (to Y.F.) and grants from the Takeda Science Foundation, the Naito Foundation, the Japan Foundation for Applied Enzymology, and Novartis Foundation (Japan) for the Promotion of Science (to Y.F.) and from the JPB Foundation and Simons Foundation (to W.K.C.).

\section{Author Contributions}

A.J.T., K.O., S.T., Y.A., Y.F., Y.H., and W.K.C. conceived and designed the study; K.O., S.T., L.D., and J.E. performed cell culture, morphological, and biochemical analyses; Y.A. performed lipidomic analysis; K.O., A.J.T., L.D., W.K.C., S.T., Y.A., and Y.F. interpreted data and wrote the manuscript.

\section{REFERENCES}

Abe Y, Honsho M, Nakanishi H, Taguchi R, Fujiki Y. 2014. Very-long-chain polyunsaturated fatty acids accumulate in phosphatidylcholine of fibroblasts from patients with Zellweger syndrome and acyl-CoA oxidase 1 deficiency. Biochim Biophys Acta 1841: 610-619. doi:10.1016/j.bbalip.2014.01.001

Barøy T, Koster J, Strømme P, Ebberink MS, Misceo D, Ferdinandusse S, Holmgren A, Hughes T, Merckoll E, Westvik J, et al. 2015. A novel type of rhizomelic chondrodysplasia punctata, RCDP5, is caused by loss of the PEX5 long isoform. Hum Mol Genet 24: 5845-5854. doi:10.1093/hmg/ddv305

Bligh EG, Dyer WJ. 1959. A rapid method of total lipid extraction and purification. Can J Biochem Physio/ 37: 911-917. doi:10.1139/y59-099

Delmaghani S, Aghaie A, Compain-Nouaille S, Ataie A, Lemainque A, Zeinali S, Lathrop M, Weil D, Petit C. 2013. DFNB40, a recessive form of sensorineural hearing loss, maps to chromosome 22q11.21-12.1. Eur J Hum Genet 11: 816-818. doi:10.1038/sj.ejhg.5201045 
Delmaghani S, Defourny J, Aghaie A, Beurg M, Dulon D, Thelen N, Perfettini I, Zelles T, Aller M, Meyer A, et al. 2015. Hypervulnerability to sound exposure through impaired adaptive proliferation of peroxisomes. Cell 163: 894-906. doi:10.1016/j.cell.2015.10.023

de Vet EC, ljlst L, Oostheim W, Wanders RJ, van den Bosch H. 1998. Alkyl-dihydroxyacetonephosphate synthase. Fate in peroxisome biogenesis disorders and identification of the point mutation underlying a single enzyme deficiency. J Biol Chem 273: 10296-10301. doi:10.1074/jbc.273.17.10296

Ebberink MS, Mooijer PA, Gootjes J, Koster J, Wanders RJA, Waterham HR. 2011. Genetic classification and mutational spectrum of more than 600 patients with a Zellweger syndrome spectrum disorder. Hum Mutat 32: 59-69. doi:10.1002/humu.21388

Fujiki Y. 2003. Peroxisome biogenesis disorders. In Encyclopedia of the human genome (ed. Cooper DN), Vol. 4, pp. 541-547. Nature Publishing Group, London.

Fujiki Y. 2016. Peroxisome biogenesis and human peroxisome-deficiency disorders. Proc Jpn Acad Ser B Phys Biol Sci 92: 463-477. doi:10.2183/pjab.92.463

Fujiki Y, Okumoto K, Kinoshita N, Ghaedi K. 2006. Lessons from peroxisome-deficient Chinese hamster ovary (CHO) cell mutants. Biochim Biophys Acta 1763: 1374-1381. doi:10.1016/j.bbamcr.2006.09.012

Fujiki Y, Okumoto K, Mukai S, Honsho M, Tamura S. 2014. Peroxisome biogenesis in mammalian cells. Front Physiol 5: 307. doi:10.3389/fphys.2014.00307.

Furuki S, Tamura S, Matsumoto N, Miyata N, Moser A, Moser HW, Fujiki Y. 2006. Mutations in the peroxin Pex26p responsible for peroxisome biogenesis disorders of complementation group 8 impair its stability, peroxisomal localization, and interaction with the Pex1p-Pex6p complex. J Biol Chem 281: 1317-1323. doi:10.1074/jbc.M510044200

Ghaedi K, Itagaki A, Toyama R, Tamura S, Matsumura T, Kawai A, Shimozawa N, Suzuki Y, Kondo N, Fujiki Y. 1999. Newly identified Chinese hamster ovary cell mutants defective in peroxisome assembly represent complementation group $\mathrm{A}$ of human peroxisome biogenesis disorders and one novel group in mammals. Exp Cell Res 248: 482-488. doi:10.1006/excr.1999.4412

Gould SJ, Valle D. 2000. Peroxisome biogenesis disorders: genetics and cell biology. Trends Genet 16: 340 345. doi:10.1016/S0168-9525(00)02056-4

Harano T, Shimizu N, Otera H, Fujiki Y. 1999. Transmembrane topology of the peroxin, Pex2p, an essential component for the peroxisome assembly. J Biochem 125: 1168-1174. doi:10.1093/oxfordjournals .jbchem.a022400

Honsho M, Yagita Y, Kinoshita N, Fujiki Y. 2008. Isolation and characterization of mutant animal cell line defective in alkyl-dihydroxyacetonephosphate synthase: localization and transport of plasmalogens to post-Golgi compartments. Biochim Biophys Acta 1783: 1857-1865. doi:10.1016/j.bbamcr.2008 .05 .018

Honsho M, Asaoku S, Fujiki Y. 2010. Posttranslational regulation of fatty acyl-CoA reductase 1, Far1, controls ether glycerophospholipid synthesis. J Biol Chem 285: 8537-8542. doi:10.1074/jbc.M109.083311

Honsho M, Abe Y, Fujiki Y. 2017. Plasmalogen biosynthesis is spatiotemporally regulated by sensing plasmalogens in the inner leaflet of plasma membranes. Sci Rep 7: 43936. doi:10.1038/srep43936.

Hosoi K, Miyata N, Mukai S, Furuki S, Okumoto K, Cheng EH, Fujiki Y. 2017. The VDAC2-BAK axis regulates peroxisomal membrane permeability. J Cell Biol 216: 709-721. doi:10.1083/jcb.201605002

Itoyama A, Honsho M, Abe Y, Moser A, Yoshida Y, Fujiki Y. 2012. Docosahexaenoic acid mediates peroxisomal elongation, a prerequisite for peroxisome division. J Cell Sci 125: 589-602. doi:10.1242/jcs.087452

Kurochkin IV, Mizuno Y, Konagaya A, Sakaki Y, Schönbach C, Okazaki Y. 2007. Novel peroxisomal protease Tysnd1 processes PTS1- and PTS2-containing enzymes involved in $\beta$-oxidation of fatty acids. EMBO $J$ 26: 835-845. doi:10.1038/sj.emboj.7601525

Matsumoto N, Tamura S, Fujiki Y. 2003a. The pathogenic peroxin Pex26p recruits the Pex1p-Pex6p AAA ATPase complexes to peroxisomes. Nat Cell Biol 5: 454-460. doi:10.1038/ncb982

Matsumoto N, Tamura S, Furuki S, Miyata N, Moser A, Shimozawa N, Moser HW, Suzuki Y, Kondo N, Fujiki Y. 2003b. Mutations in novel peroxin gene PEX26 that cause peroxisome-biogenesis disorders of complementation group 8 provide a genotype-phenotype correlation. Am J Hum Genet 73: 233-246. doi:10.1086/377004

Miyazawa S, Osumi T, Hashimoto T, Ohno K, Miura S, Fujiki Y. 1989. Peroxisome targeting signal of rat liver acyl-coenzyme A oxidase resides at the carboxy terminus. Mol Cell Biol 9: 83-91. doi:10.1128/ MCB.9.1.83

Mukai S, Fujiki Y. 2006. Molecular mechanisms of import of peroxisome-targeting signal type 2 (PTS2) proteins by PTS2 receptor Pex7p and PTS1 receptor Pex5pL. J Biol Chem 281: 37311-37320. doi:10.1074/jbc .M607178200

Neuhaus C, Eisenberger T, Decker C, Nagl S, Blank C, Pfister M, Kennerknecht I, Mueller-Hofstede C, Issa PC, Heller R, et al. 2017. Next-generation sequencing reveals the mutational landscape of clinically diagnosed Usher syndrome: copy number variations, phenocopies, a predominant target for translational 
read-through, and PEX26 mutated in Heimler syndrome. Mol Genet Genom Med 5: 531-552. doi: 10.1002/mgg3.312

Okumoto K, Kametani Y, Fujiki Y. 2011. Two proteases, trypsin domain-containing 1 (Tysnd1) and peroxisomal Lon protease (PsLon), cooperatively regulate fatty-acid $\beta$-oxidation in peroxisomal matrix. J Biol Chem 286: 44367-44379. doi:10.1074/jbc.M111.285197

Osumi T, Tsukamoto T, Hata S, Yokota S, Miura S, Fujiki Y, Hijikata M, Miyazawa S, Hashimoto T. 1991. Aminoterminal presequence of the precursor of peroxisomal 3-ketoacyl-CoA thiolase is a cleavable signal peptide for peroxisomal targeting. Biochem Biophys Res Commun 181: 947-954. doi:10.1016/0006-291X(91) 92028-1

Otera H, Okumoto K, Tateishi K, Ikoma Y, Matsuda E, Nishimura M, Tsukamoto T, Osumi T, Ohashi K, Higuchi $\mathrm{O}$, et al. 1998. Peroxisome targeting signal type 1 (PTS1) receptor is involved in import of both PTS1 and PTS2: studies with PEX5-defective CHO cell mutants. Mol Cell Biol 18: 388-399. doi:10.1128/ MCB.18.1.388

Otera H, Nishimura M, Setoguchi K, Mori T, Fujiki Y. 2001. Biogenesis of nonspecific lipid transfer protein and sterol carrier protein $\mathrm{x}$ : studies using peroxisome assembly-defective pex cell mutants. J Biol Chem 276: 2858-2864. doi:10.1074/jbc.M007730200

Shimozawa N, Tsukamoto T, Suzuki Y, Orii T, Fujiki Y. 1992. Animal cell mutants represent two complementation groups of peroxisome-defective Zellweger syndrome. J Clin Invest 90: 1864-1870. doi:10.1172/ $\mathrm{JCl} 116063$

Steinberg S, Chen L, Wei L, Moser A, Moser H, Cutting G, Braverman N. 2004. The PEX gene screen: molecular diagnosis of peroxisome biogenesis disorders in the Zellweger syndrome spectrum. Mol Genet Metab 83: 252-263. doi:10.1016/j.ymgme.2004.08.008

Steinberg SJ, Dodt G, Raymond GV, Braverman NE, Moser AB, Moser HW. 2006. Peroxisome biogenesis disorders. Biochim Biophys Acta 1763: 1733-1748. doi:10.1016/j.bbamcr.2006.09.010

Stowe RC, Agarwal S. 2017. Novel PEX26 mutation causing Zellweger syndrome presenting as feeding intolerance and hypotonia. Pediat Neurol 75: 96-97. doi:10.1016/j.pediatrneurol.2017.06.012

Suzuki Y, Shimozawa N, Yajima S, Yamaguchi S, Orii T, Hashimoto T. 1991. Effects of sodium 2-[5-(4-chlorophenyl)pentyl]-oxirane-2-carboxylate (POCA) on fatty acid oxidation in fibroblasts from patients with peroxisomal diseases. Biochem Pharmacol 41: 453-456. doi:10.1016/0006-2952(91)90544-F

Swinkels BW, Gould SJ, Bodnar AG, Rachubinski RA, Subramani S. 1991. A novel, cleavable peroxisomal targeting signal at the amino-terminus of the rat 3-ketoacyl-CoA thiolase. EMBO J 10: 3255-3262. doi:10.1002/j.1460-2075.1991.tb04889.x

Tamura S, Matsumoto N, Takeba R, Fujiki Y. 2014. AAA peroxins and their recruiter Pex26p modulate the interactions of peroxins involved in peroxisomal protein import. J Biol Chem 289: 24336-24346. doi: 10.1074/jbc.M114.588038

Tanaka AJ, Cho MT, Willaert R, Retterer K, Zarate YA, Bosanko K, Stefans V, Oishi K, Williamson A, Wilson GN, et al. 2017. De novo variants in EBF3 are associated with hypotonia, developmental delay, intellectual disability, and autism. Cold Spring Harb Mol Case Stud 3: a002097. doi:10.1101/mcs.a002097

Tsukamoto T, Yokota S, Fujiki Y. 1990. Isolation and characterization of Chinese hamster ovary cell mutants defective in assembly of peroxisomes. J Cell Biol 110: 651-660. doi:10.1083/jcb.110.3.651

Wanders RJ. 2004. Metabolic and molecular basis of peroxisomal disorders: a review. Am J Med Genet A 355375. doi:10.1002/ajmg.a.20661

Wanders RJ, Waterham HR. 2006. Biochemistry of mammalian peroxisomes revisited. Annu Rev Biochem 75: 295-332. doi:10.1146/annurev.biochem.74.082803.133329

Waterham HR, Ebberink MS. 2012. Genetics and molecular basis of human peroxisome biogenesis disorders. Biochim Biophys Acta 1822: 1430-1441. doi:10.1016/j.bbadis.2012.04.006

Weller S, Gould SJ, Valle D. 2003. Peroxisome biogenesis disorders. Annu Rev Genomics Hum Genet 4: 165211. doi:10.1146/annurev.genom.4.070802.110424

Weller S, Cajigas I, Morrell J, Obie C, Steel G, Gould SJ, Valle D. 2005. Alternative splicing suggests extended function of PEX26 in peroxisome biogenesis. Am J Hum Genet 76: 987-1007. doi:10.1086/430637 


\section{COLD SPRING HARBOR Molecular Case Studies}

\section{A newly identified mutation in the PEX26 gene is associated with a milder form of Zellweger spectrum disorder}

Akemi J. Tanaka, Kanji Okumoto, Shigehiko Tamura, et al.

Cold Spring Harb Mol Case Stud 2019, 5: a003483 originally published online November 16, 2018 Access the most recent version at doi: $10.1101 /$ mcs.a003483
Supplementary http://molecularcasestudies.cshlp.org/content/suppl/2019/01/10/mcs.a003483.D Material C1
References This article cites 44 articles, 14 of which can be accessed free at: http://molecularcasestudies.cshlp.org/content/5/1/a003483.full.html\#ref-list-1
License This article is distributed under the terms of the Creative Commons Attribution-NonCommercial License, which permits reuse and redistribution, except for commercial purposes, provided that the original author and source are credited.
Email Alerting Receive free email alerts when new articles cite this article - sign up in the box at the Service top right corner of the article or click here.

